\title{
A Prospective Randomized, Controlled, Double-Blind Trial of the Efficacy Using Centella Cream for Scar Improvement
}

\author{
Kamonwan Jenwitheesuk (D), Porntip Rojsanga, \\ Bowornsilp Chowchuen, and Palakorn Surakunprapha
}

Division of Plastic and Reconstructive Surgery, Department of Surgery, Faculty of Medicine, Khon Kaen University, Khon Kaen 40000, Thailand

Correspondence should be addressed to Kamonwan Jenwitheesuk; kamoje@kku.ac.th

Received 13 April 2018; Revised 3 August 2018; Accepted 16 August 2018; Published 17 September 2018

Academic Editor: Gioacchino Calapai

Copyright ( 2018 Kamonwan Jenwitheesuk et al. This is an open access article distributed under the Creative Commons Attribution License, which permits unrestricted use, distribution, and reproduction in any medium, provided the original work is properly cited.

Objective. This study was performed to evaluate the efficacy of Centella asiatica extract in cream, a preparation for the prevention of scar development of the split-thickness skin graft (STSG) donor site. Methods. A prospective randomized, double-blind control study was performed to evaluate the efficacy of Centella cream in 30 patients who underwent a STSG operation. Both Centella cream and placebo were applied equally to the donor site at least 2 weeks after epithelialization was completed. A scar assessment using the Vancouver Scar Scale (VSS) was taken at 4, 8, and 12 weeks. Results. Of the original 30 patients, 23 patients completed evaluation. There were significant differences in pigmentation parameter of VSS and comparative total VSS scores between 4 and 12 weeks in Centella cream group. Conclusion. The effect of Centella cream on scar development of a STSG operation may be attainable in terms of better pigmentation. By means of objective measurements and longer follow-up times, Centella cream may prove to be an alternative product for hypertrophic scar amelioration.

\section{Introduction}

Wound healing is a process that takes place with almost all medical treatments. The history of the wound care dates back to the days when natural substances, such as honey and other various remedies, were the norm for treatment since 2600 2200 BCE [1]. Later studies found that natural substances contained in herbs and plants have many positive properties that assist in and enhance the wound healing process, substances such as antioxidants, anti-inflammatories, and antibacterial agents [2]. Many species of plants support the theory that herbs have served a major role in assisting the process of recovery and healing. Studies from different parts of the world have produced concrete findings that support such theories in the era of modern medicine. Evidence stems from research regarding plants and herb usage for treating wounds in different geographical locations, countries such as Africa [3, 4], India [5], China [6] Thai [7], and even the United States, Canada, or Europe [8].

When wounds occur, the chances of a scar forming are greatly increased; scars usually have negative impact on patient. There are many methodologies such as occlusive dressings, compression therapy, intralesional corticosteroid injections, radiation therapy, laser therapy, interferon therapy, and topical silicone gel application, and herbal extracts have been prescribed as the norm. The high cost of these treatments has been the greatest obstacle for patients to continue with treatment, especially in developing countries. "Ugly scars" is a term referring to scar contracture, stretching or hypertrophic scarring resulting from abnormal response by fibroblasts during the proliferative stage and imbalance between collagen synthesis and degradation during the remodeling stage [9]. Nowadays, herbs have an important role in restoring the healing wound process and ameliorating scar. Current studies on C. asiatica have been conducted to improve the outcome of the wound healing process in small wound types and hypertrophic scar as well as burns, psoriasis, and scleroderma [10-14].

Centella asiatica, also commonly known as Gotu kola, is a small plant that depends on the soil with water trapped, as a herbaceous that originates from Asia. It is an annual plant of the family Apiaceae. This plant has been used in folk medicine 

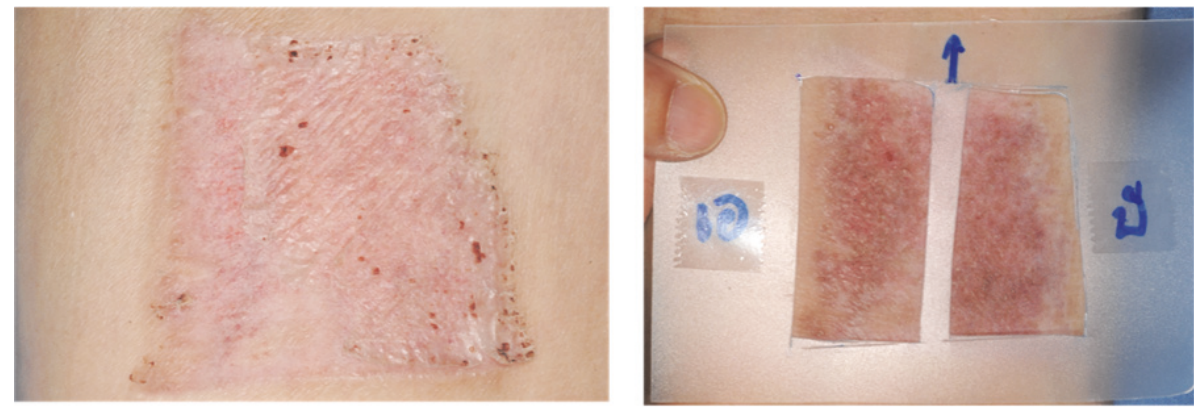

Figure 1: Two-hole template using which patients have to apply the Centella and placebo cream in the frame.

as well as in western medicine [15]. This study was performed to evaluate the efficacy of Centella asiatica extract in a cream preparation for the prevention of scar development on the STSG donor site.

\section{Methods}

2.1. Design Overview. All patients who participated consented to join the study on a voluntary basis as the donor site of STSG. Subjects were divided randomly into 2 groups, with various cream applied to each part of the donor's scar site. Cream A $(7 \% \mathrm{w} / \mathrm{w}$ Centella asiatica extract in cream preparation) or Cream B (placebo) was randomly applied on the subjects. The gels were applied for a total treatment period of 12 weeks. The assessment was conducted by one experienced nurse who was blinded to the subject grouping and was trained to administer all the assessments in standardized manner.

2.2. Setting and Participants. From January 2014 to February 2015, 36 patients who underwent split-thickness skin graft harvesting were enrolled in this study, but six patients were excluded because they declined to participate at the Outpatient Unit, Department of Surgery, Faculty of Medicine Srinagarind Hospital. All 30 patients in this study were aged over 20 years and met the inclusion criteria. This study was approved by Khon Kaen University Ethics Committees for Human Research.

\section{Inclusion Criteria}

(1) The donor site of the patients who underwent STSG operation completed more than 14 days of epithelialization.

(2) All of the participants were 20 years or older.

\section{Exclusion Criteria}

(1) Patients with critical illnesses such as those with systemic infection or hemodynamic instability.

(2) Patients with a major acute or chronic medical illness that could have impact on the wound healing process.

(3) Patients who were pregnant.

(4) Patients who could not read the Thai language.

(5) Patients who declined to participate.
2.3. Sample Size. 30 voluntary patients were included in this study. The donor site of skin graft in each subject was divided into 2 parts, with different treatments randomly applied to each part. For sample analysis, with 23 subjects per method, the statistical power to remark a mean difference of 1 unit on the rating scale, assuming an SD of 1.71 , was $80 \%$. A 2 -tailed test with type 1 error rate $5 \%$ was supposed. In statistical method, 1.00 corresponded to $\mathrm{Mu}(\mathrm{M})$ and 0.02 to the Beta $(\beta)$. Concerning defense against the withdrawal of the patients, it was necessary to raise the number of patients of each group to be 30 .

2.4. Randomization and Interventions. The Centella asiatica was prepared by being extracted with $70 \%$ alcohol in cream preparation (Chao Phya Abhaibhubejhr Hospital, Prachin Buri, Thailand). It was formulated from $7 \% \mathrm{w} / \mathrm{w}$ Centella extract, 100 gram, combined with Centella extract 7 g., cetyl alcohol 15 g., stearyl alcohol 12 g., mineral oil 5 g., cetomacrogol-1,000 3 g., propylene glycol 1 g., paraben concentrate $1.5 \mathrm{~g}$, and water refill for total of $100 \mathrm{~g}$. for the whole combination. The Centella extract comprised asiaticoside $5.12 \%$ and madecassoside $5.1 \%$. The placebo cream was similar in color and consistency to the Centella asiatica extract cream and was packed in the same sealed packages. For the composition, it was the same as Centella asiatica extract cream except $7 \mathrm{~g}$. of paraben concentrate. Centella and placebo cream were marked A or B. The patients were advised to clean their hands before applying each cream and to use the template (Figure 1). After placing the template on the wound, the patient had to gently apply approximately 1 gram of each cream and wait until they were completely absorbed. This application was done twice daily. Each patient was scheduled for follow-up at 4, 8, and 12 weeks (Figure 2).

2.5. Outcomes and Measurements. Patient demographic data were recorded. The scars were examined and rated using the Vancouver Scar Scale (Table 1) to determine pigmentation, vascularity, pliability, and height. The digital photos of each scar were also recorded by using a digital camera each time the assessment was performed, and the photos taken were standardized with fixed distance and lighting. A digital camera was used to ensure that the images taken were clear and comparable.

The Vancouver Scar Scale measured vascularity, pliability, and height, each on a 3- to 6-point ordinal scale; pigmentation 
TABLE 1: Vancouver Scar Scale (VSS).

\begin{tabular}{lccccc}
\hline Score & $\mathbf{0}$ & $\mathbf{1}$ & $\mathbf{2}$ & $\mathbf{3}$ & $\mathbf{4}$ \\
\hline Vascularity & Normal & Pink & Red & Purple & \\
Pigmentation & Normal & Hypopigmentation & Mixed & Hyperpigmentation & \\
Pliability & Normal & Supple & Yielding & Firm & Ropes \\
Height & Flat & $<2 \mathrm{~mm}$ & $2-5 \mathrm{~mm}$ & $>5 \mathrm{~mm}$ & Contractures \\
\hline
\end{tabular}

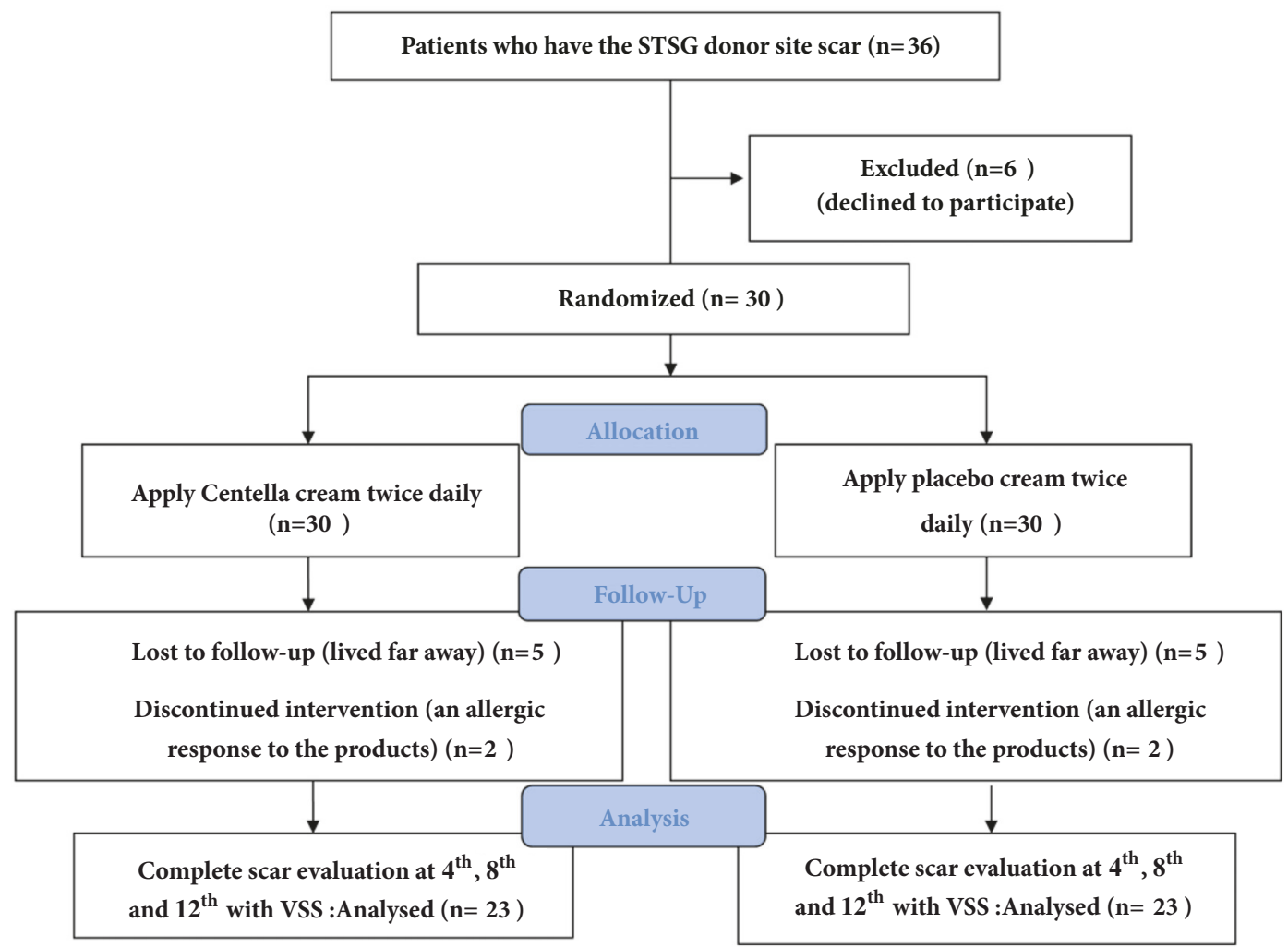

FIGURE 2: Diagram of study protocol that was initiated.

was measured on a 3-point categorical scale. The results were recorded and patients identified as to which of the 2 groups they belonged after the protocol was finished. If the treatment decreased in the score of each parameter, the result concluded with improvements. If the score was the same or higher, no response was reported.

2.6. Statistical Analysis. Greenhouse-Geisser correction ( $\mathrm{p}$ value) and one-way repeated measures ANOVA were used to assess two more groups who were participants in the same group. All statistical analyses were operated using SPSS 16.0 software (SPSS, Chicago, IL.). A p value equal to or below 0.05 was regarded as statistically significant

\section{Results}

Only 23 of 30 patients completed the study protocol. 2 patients were excluded due to rash at the scar, which may have been caused by an allergic response to the products. 5 patients were lost to follow-up because they lived far away. Of 23 patients, there were 13 males and 10 females. The average age was 54 years old (range: $20-65$ years old). As shown in Table 2 and Figures 3-7, differences within groups are as follows: For the Centella cream group, there were differences from baseline including the pigmentation score at 8 and 12 weeks and between 4 and 12 weeks $(-0.443$, p value $0.019 ;-0.707, p$ value $0.001 ;-0.557$, p value 0.001$)$ and the overall Vancouver Scar Scale scores between 4 and 12 weeks $(-1.279$, p value 0.041). However, for height, it was worse at 4 weeks $(0.300, \mathrm{p}$ value 0.043 ). For the placebo group, there were 2 differences from the baseline including the pigmentation score between 4 and 12 weeks $(-0.399, \mathrm{p}$ value 0.020$)$ and after 12 weeks (0.549 , p value 0.002 ), while the pliability and the height scores of both groups were compared before and after treatment and still were not different.

\section{Discussion}

The split-thickness skin graft donor site is a superficial partially thickness wound in which losing the epidermis and part of the dermis exists. Epithelialization is the natural act of healing dermal tissue resulting in minimal or no scarring 
TABLE 2: Comparison within groups after 12 weeks of both groups.

\begin{tabular}{|c|c|c|c|c|}
\hline Vancouver Scar Scale & Centella cream & Contrast & 95\% CI & P-value \\
\hline After & week 4th & 0.400 & $-0.799-1.599$ & 0.510 \\
\hline After & week 8th & -0.089 & $-1.312-1.133$ & 0.885 \\
\hline After & week 12th & -0.879 & $-2.102-0.344$ & 0.157 \\
\hline Between & $8 \& 4$ weeks & -0.489 & $-1.712-0.733$ & 0.429 \\
\hline Between & $12 \& 4$ weeks & -1.279 & $-2.502--0.056$ & $0.041^{*}$ \\
\hline Between & $12 \& 8$ weeks & -0.789 & $-2.020-0.441$ & 0.206 \\
\hline Vancouver Scar Scale & Placebo & & & \\
\hline After & week 4th & 0.150 & $-1.049-1.349$ & 0.805 \\
\hline After & week 8th & 0.312 & $-0.911-1.535$ & 0.614 \\
\hline After & week 12th & -0.793 & $-2.016-0.429$ & 0.201 \\
\hline Between & $8 \& 4$ weeks & 0.162 & $-1.061-1.385$ & 0.794 \\
\hline Between & $12 \& 4$ weeks & -0.943 & $-2.166-0.279$ & 0.129 \\
\hline Between & $12 \& 8$ weeks & -1.105 & $-2.336-0.125$ & 0.078 \\
\hline Vascularity & Centella cream & & & \\
\hline After & week 4th & 0.100 & $-0.426-0.626$ & 0.707 \\
\hline After & week 8th & -0.055 & $-0.591-0.481$ & 0.838 \\
\hline After & week 12th & -0.213 & $-0.749-0.323$ & 0.432 \\
\hline Between & $8 \& 4$ weeks & -0.155 & $-0.691-0.381$ & 0.567 \\
\hline Between & $12 \& 4$ weeks & -0.313 & $-0.849-0.223$ & 0.249 \\
\hline Between & $12 \& 8$ weeks & -0.158 & $-0.697-0.381$ & 0.563 \\
\hline Vascularity & Placebo & & & \\
\hline After & week 4 th & -0.050 & $-0.576-0.476$ & 0.851 \\
\hline After & week 8th & -0.051 & $-0.587-0.485$ & 0.850 \\
\hline After & week 12th & -0.367 & $-0.903-0.169$ & 0.177 \\
\hline Between & $8 \& 4$ weeks & -0.001 & $-0.537-0.535$ & 0.996 \\
\hline Between & $12 \& 4$ weeks & -0.317 & $-0.853-0.219$ & 0.244 \\
\hline Between & $12 \& 8$ weeks & -0.316 & $-0.855-0.224$ & 0.248 \\
\hline Pigmentation & Centella cream & & & \\
\hline After & week 4th & -0.150 & $-0.478-0.178$ & 0.366 \\
\hline After & week 8th & -0.443 & $-0.777--0.109$ & $0.010^{*}$ \\
\hline After & week 12 th & -0.707 & $-1.041--0.373$ & $0.001^{*}$ \\
\hline Between & $8 \& 4$ weeks & -0.293 & $-0.627-0.041$ & 0.084 \\
\hline Between & $12 \& 4$ weeks & -0.557 & $-0.891--0.223$ & $0.001^{*}$ \\
\hline Between & $12 \& 8$ weeks & -0.263 & $-0.599-0.073$ & 0.124 \\
\hline Pigmentation & Placebo & & & \\
\hline After & week 4th & -0.150 & $-0.478-0.178$ & 0.366 \\
\hline After & week 8th & -0.233 & $-0.567-0.101$ & 0.170 \\
\hline After & week 12th & -0.549 & $-0.883--0.215$ & $0.002^{*}$ \\
\hline Between & $8 \& 4$ weeks & -0.083 & $-0.417-0.251$ & 0.624 \\
\hline Between & $12 \& 4$ weeks & -0.399 & $-0.733--0.065$ & $0.020^{*}$ \\
\hline Between & $12 \& 8$ weeks & -0.316 & $-0.652-0.020$ & 0.065 \\
\hline Pliability & Centella cream & & & \\
\hline After & week 4th & 0.200 & $-0.202-0.602$ & 0.326 \\
\hline After & week 8th & 0.179 & $-0.231-0.589$ & 0.389 \\
\hline After & week 12th & -0.137 & $-0.547-0.273$ & 0.509 \\
\hline Between & $8 \& 4$ weeks & -0.021 & $-0.431-0.389$ & 0.919 \\
\hline Between & $12 \& 4$ weeks & -0.337 & $-0.747-0.073$ & 0.106 \\
\hline Between & $12 \& 8$ weeks & -0.316 & $-0.728-0.097$ & 0.132 \\
\hline Pliability & Placebo & & & \\
\hline After & week 4th & 0.150 & $-0.252-0.552$ & 0.461 \\
\hline After & week 8th & 0.312 & $-0.098-0.722$ & 0.134 \\
\hline After & week 12th & -0.004 & $-0.414-0.406$ & 0.985 \\
\hline
\end{tabular}


TABLE 2: Continued.

\begin{tabular}{lcccc}
\hline Vancouver Scar Scale & Centella cream & Contrast & 95\% CI & P-value \\
\hline Between & $8 \& 4$ weeks & 0.162 & $-0.248-0.572$ & 0.435 \\
Between & $12 \& 4$ weeks & -0.154 & $-0.564-0.256$ & 0.458 \\
Between & $12 \& 8$ weeks & -0.316 & $-0.728-0.097$ & 0.132 \\
\hline Height & Centella cream & & & \\
\hline After & week 4th & 0.300 & $0.009-0.591$ & $0.043^{*}$ \\
After & week 8th & 0.229 & $-0.067-0.525$ & 0.129 \\
After & week 12th & 0.176 & $-0.120-0.473$ & 0.241 \\
Between & $8 \& 4$ weeks & -0.071 & $-0.367-0.225$ & 0.636 \\
Between & $12 \& 4$ weeks & -0.124 & $-0.420-0.173$ & 0.410 \\
Between & $12 \& 8$ weeks & -0.053 & $-0.351-0.246$ & 0.727 \\
\hline Height & Placebo & & & \\
\hline After & week 4th & 0.200 & $-0.091-0.491$ & 0.176 \\
After & week 8th & 0.284 & $-0.012-0.581$ & 0.060 \\
After & week 12th & 0.126 & $-0.170-0.423$ & 0.400 \\
Between & $8 \& 4$ weeks & 0.084 & $-0.212-0.381$ & 0.575 \\
Between & $12 \& 4$ weeks & -0.074 & $-0.370-0.223$ & 0.623 \\
Between & $12 \& 8$ weeks & -0.158 & $-0.456-0.140$ & 0.296 \\
\hline
\end{tabular}

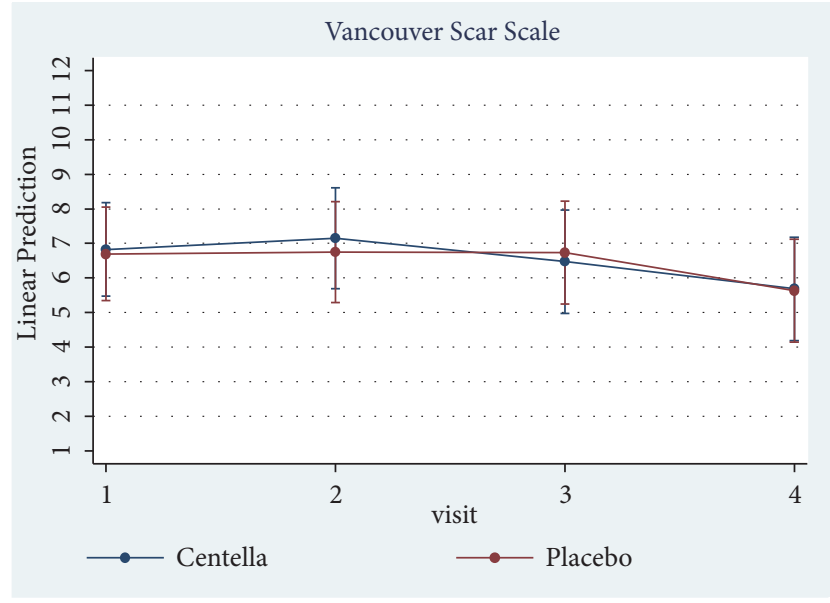

FIGURE 3: Comparison of Vancouver scar scores within groups after 12 weeks.

[16]. In most cases, scars occur if the depth reaches the dermis layer; the exposed area of the scar can be more problematic. Treatment for scars can be difficult, and in some cases the skin cannot return to its normal condition causing additional suffering to the patient. Some patients complained about discoloration, both hyperpigmentation and hypopigmentation. When hypertrophic scar or keloid developed, it may induce itching, pain, and uninviting scar damage, sometimes in the form of scar contracture which may cause organ dysfunction. In some cases, patients were unhappy and expressed a great deal of regret, anger, rejection, and isolation despair [17]. The knowledge of scar protection/prevention and causes of the scar is an important factor and helps reduce its severity. However, some Asians displayed a condition referred to as "Fitzpatrick Skin" (type III or type

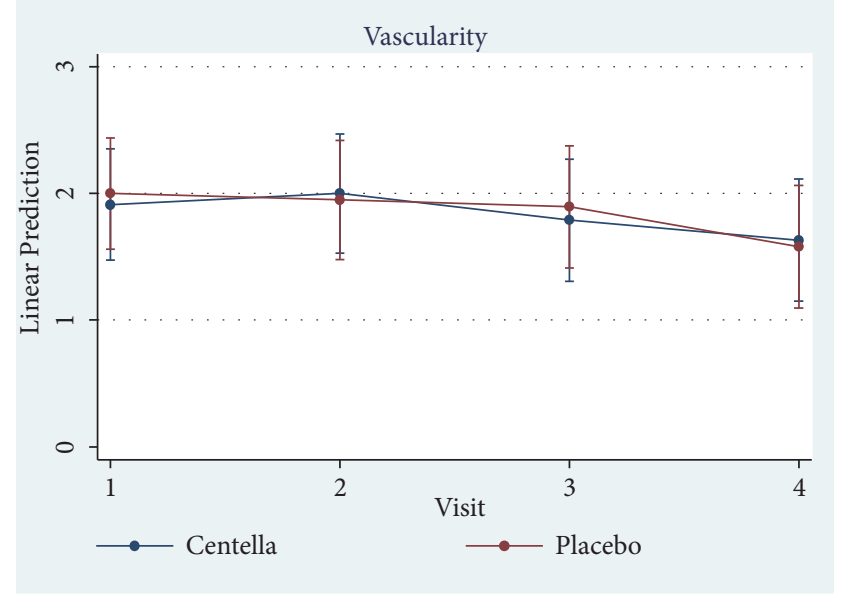

FIGURE 4: Comparison of vascularity scores within groups after 12 weeks.

IV): commonly known as hypervascular, hyperpigmented, hypopigmented, or hypertrophic scars when other related characteristics are the anatomic region, patient's skin type or genetic factors, nature of injury, skin tension, and prolonged inflammatory process [18]. Numerous attempts have been made to introduce natural substances to reduce scars such as onion extract $[19,20]$, resveratrol in grape's skin [21], curcumin [22], and Centella [23].

Scar protection applications can be made by starting from coagulation, inflammation, and proliferation phase, which tried to make each phase without any complications and was time consuming. In the remodeling phase, collagen was rearranged and was broken by enzyme matrix metalloproteinase (MMPs), which is controlled by tissue inhibitors of MMP (TIMPs) [24]. The balance between regeneration and 


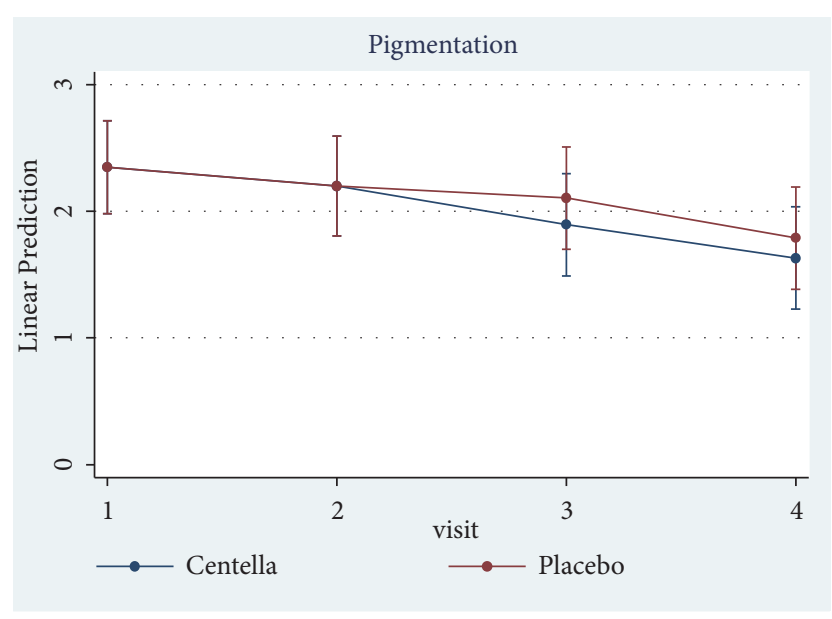

Figure 5: Comparison of pigmentation scores within groups after 12 weeks.

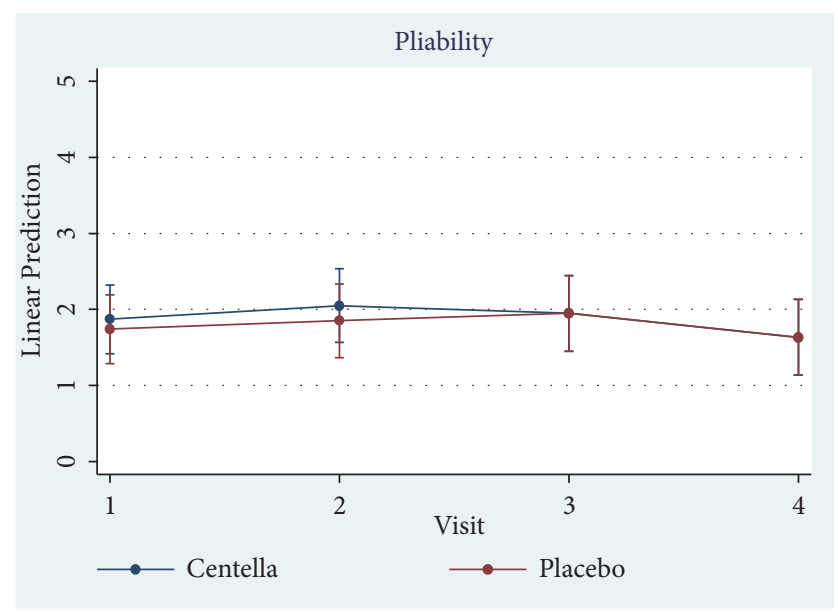

FIGURE 6: Comparison of pliability scores within groups after 12 weeks.

degradation of collagen was initiated during the time periods of 6 months to 1 year. The scar was entirely abnormal in appearance, the architectural arrangement of collagen, and ECM. The strategy for minimized scar needed many factors like efficiently control inflammation [25] and low levels of cytokines such as TGF $\beta \mathrm{I}$, TGF $\beta \mathrm{II}$, and platelet-derived growth factor $[26,27]$ but high levels of TGF $\beta$ III [26-28]. TGF $\beta$ I and TGF $\beta$ II played a role in activating proliferation of fibroblasts, whereas TGF $\beta$ III was antagonist and that is why it could prevent scar formation [29].

Prior studies have shown the effectiveness of C. asiatica extract in promotion of wound healing and prevention of hypertrophic scars $[19,30,31]$. The active compounds of C. asiatica responsible for those activities are pentacyclic triterpenes, including asiaticoside, and madecassoside. In vitro study demonstrated that asiaticoside decreased fibroblast proliferation in a dose-related manner and reduced the expression of both TGF- $\beta$ I and TGF- $\beta$ II at the transcriptional and translational level [32]. Asiaticoside also slows

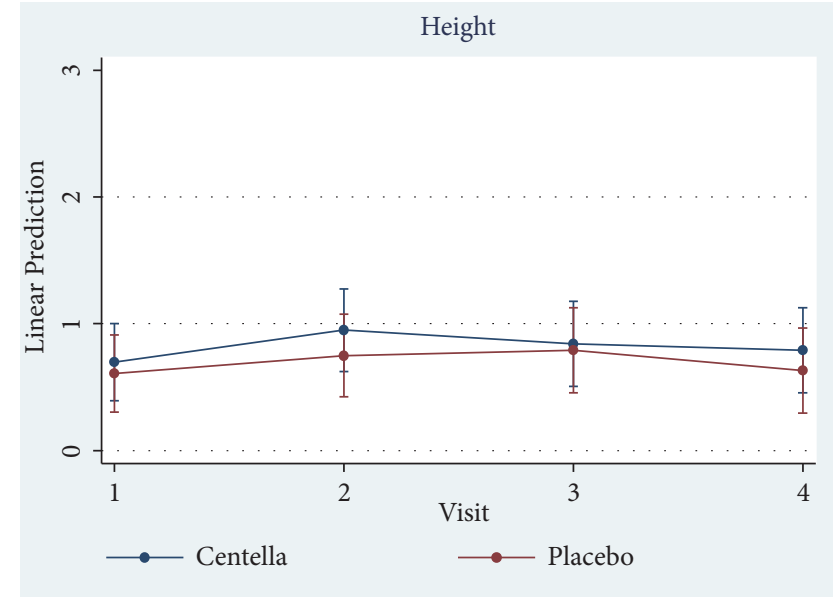

FIGURE 7: Comparison of height scores within groups after 12 weeks.

down scar formation possibility by increasing the activity process of Smad7 which is a negative regulator of TGF- $\beta$ signaling [33]. The other active composition, madecassoside, is related to inhibiting the migration of fibroblasts from keloids [34]. Both active chemical substances promote $C$. asiatica to induce fibroblast proliferation and collagen synthesis. It involves the improvement of the tensile strength of newly formed skin and stimulation of maturation of the scar by the production of type I collagen. Inversely, the expression of TGF- $\beta$ I in hypertrophic scars and keloid is reduced [32, $34,35]$. Both asiaticoside and madecassoside affected the healing process mechanism in which inflammatory, proliferation, and remodeling phases initiate the improvement of wound healing and scar prevention [10]. In the case of animal research they showed effective result of diminished hypertrophic scar [30]. Numerous data confirmed that $C$. asiatica extract in a combination form with other herbs could prevent abnormal scars from median sternotomy or split-thickness skin graft donor sites; however, no exact demonstration revealed that one was stronger for preventing scar $[19,31]$. The aim of this study was to evaluate the efficacy of Centella cream with only one chemical substance, not combined with other herbal substances, on the prevention of scar development. Our study revealed that Centella cream improved scar outcomes against placebo. The Centella cream significantly improved the overall Vancouver scores between 4 and 12 weeks and pigmentation from the baseline since 8th week, in comparison with the improved pigmentation from the baseline since the 12 th week in the placebo group. This evidence concluded that the nature of scar development of the donor site of the split- thickness skin grafts got better over time, ameliorating by Centella effect. Figures 8 and 9 demonstrated the better outcome in skin pigmentation after applying the Centella cream. In this study, an allergic dermatitis was observed in 2 patients. Gomes reported in the reported case that the patient had contact dermatitis due to Centella asiatica extract [36]. Since the allergic reaction occurred with both Centella cream and placebo, the ingredients of the placebo may be responsible for the allergic 


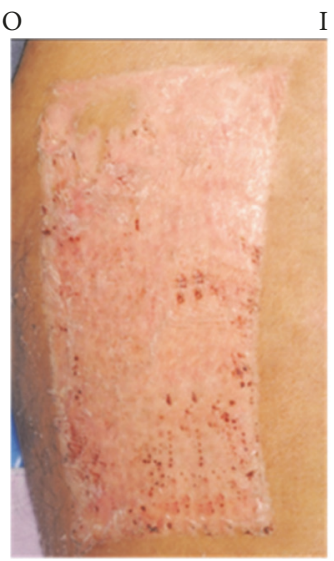

The first visit
I O

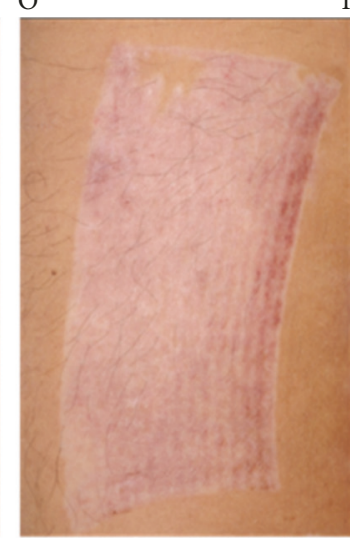

$4^{\text {th }}$ week
I O

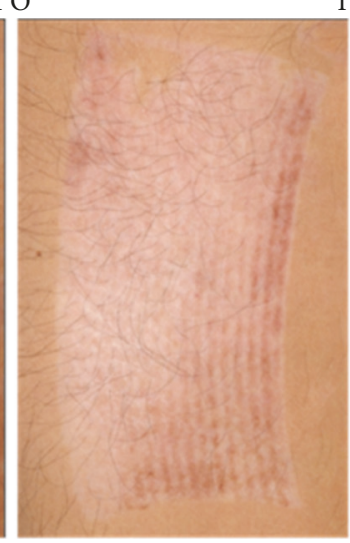

$8^{\text {th }}$ week
I O

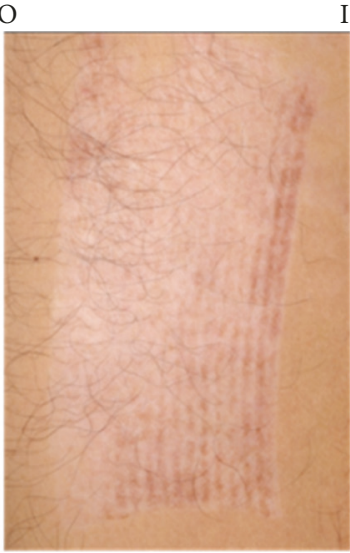

$12^{\text {th }}$ week

FIGURE 8: A 58-year-old male patient with a split-thickness skin graft harvested from right thigh. Centella cream was applied at the outer part with placebo at the inner part of thigh (I: inner part, O: outer part).
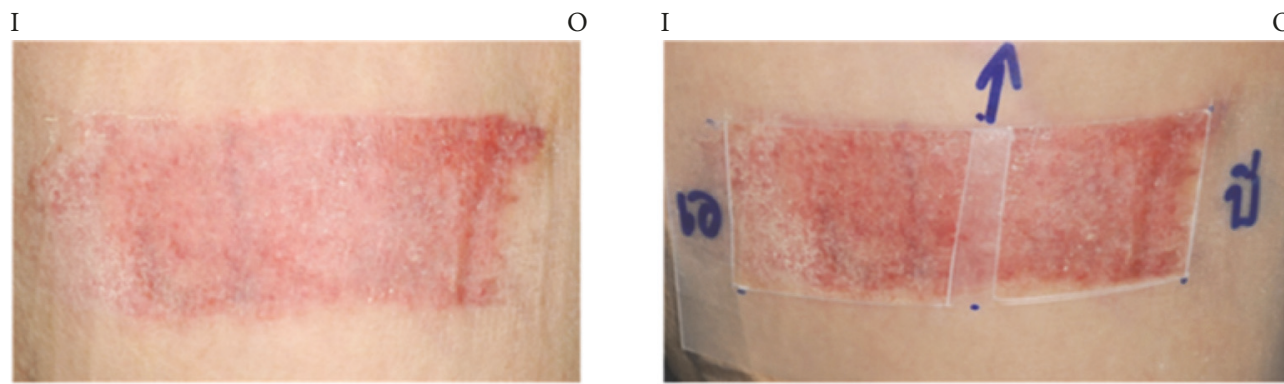

The first visit

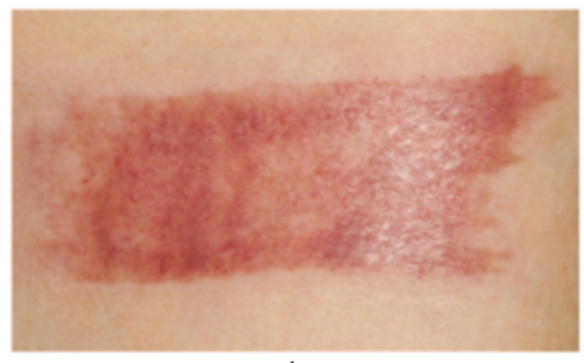

$4^{\text {th }}$ week

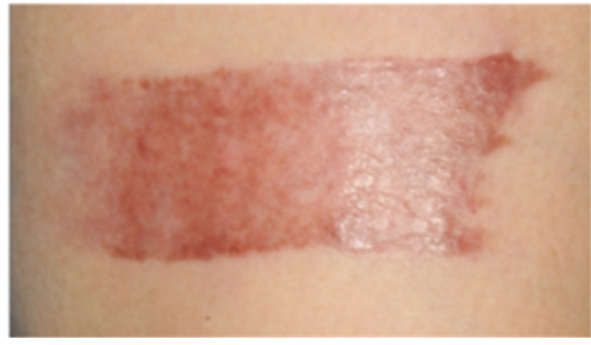

$12^{\text {th }}$ week

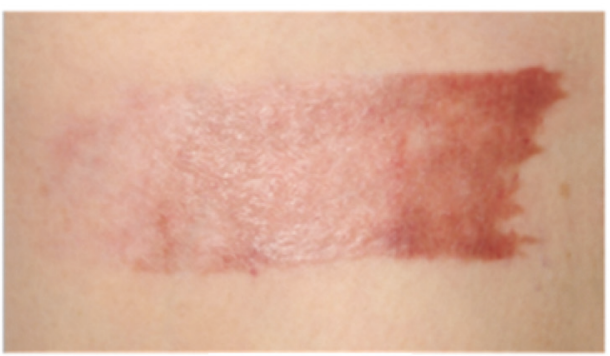

$8^{\text {th }}$ week O

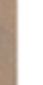


dermatitis. Previous reports showed that contact dermatitis developed when paraben-containing products were applied [37].

The efficacy of C. asiatica formulation may be affected by the release of active compounds from the formulation. The animal (rat) model demonstrated the promoted cellular proliferation and collagen synthesis effects of the aqueous extract C. asiatica. The gel formulation provided significantly better healing outcome than the ointment and cream formulations [38].

The VSS is more subjective measurement. Studies with longer follow-ups may be required to confirm the benefits of this product. In the future, the dosage and the manner evaluation of efficacy of Centella asiatica need standardized experimentation in the healing process and scar prevention.

\section{Conclusion}

The effect of Centella cream on scar development of the donor site of the split- thickness skin grafts may be attainable in terms of better pigmentation. By means of objective measurements and longer follow-up times, Centella cream may prove to be an alternative product for hypertrophic scar amelioration.

\section{Data Availability}

The data used to support the findings of this study are available from the corresponding author upon request.

\section{Conflicts of Interest}

The authors have no financial interest or commercial association with any information mentioned in this article.

\section{Acknowledgments}

This study was supported by a grant from Faculty of Medicine, Khon Kaen University (KKU). The authors wish to thank Faculty of Medicine and the Tawanchai Project, KKU, for their support and professor James A. Will for assistance with the English-language presentation of the manuscript under the aegis of the Publication Clinic, Research Affairs, Faculty of Medicine, KKU.

\section{References}

[1] R. Zubair and N. Aziz, "As smooth as honey-the historical use of honey as topical medication," JAMA Dermatology, vol. 151, no. 10, p. 1102, 2015.

[2] S. A. Meo, S. A. Al-Asiri, A. L. Mahesar, and M. J. Ansari, "Role of honey in modern medicine," Saudi Journal of Biological Sciences, vol. 24, no. 5, pp. 975-978, 2017.

[3] C. Agyare, Y. D. Boakye, E. O. Bekoe, A. Hensel, S. O. Dapaah, and T. Appiah, "Review: African medicinal plants with wound healing properties," Journal of Ethnopharmacology, vol. 177, pp. 85-100, 2016.

[4] N. C. Dlova and M. A. Ollengo, "Traditional and ethnobotanical dermatology practices in Africa," Clinics in Dermatology, vol. 36, no. 3, pp. 353-362, 2018.
[5] J. Sharma, S. Gairola, Y. P. Sharma, and R. D. Gaur, "Ethnomedicinal plants used to treat skin diseases by Tharu community of district Udham Singh Nagar, Uttarakhand, India," Journal of Ethnopharmacology, pp. 140-206, 2014.

[6] Q. Li, Y. Niu, P. Xing, and C. Wang, "Bioactive polysaccharides from natural resources including Chinese medicinal herbs on tissue repair," Chinese Medicine, vol. 13, no. 1, 2018.

[7] O. Neamsuvan and P. Bunmee, "A survey of herbal weeds for treating skin disorders from Southern Thailand: Songkhla and Krabi Province," Journal of Ethnopharmacology, vol. 193, pp. 574-585, 2016.

[8] M. Sharifi-Rad, D. Mnayer, M. F. Morais-Braga et al., "Echinacea plants as antioxidant and antibacterial agents: From traditional medicine to biotechnological applications," Phytotherapy Research, vol. 32, no. 9, pp. 1653-1663, 2018.

[9] C. J. M. van den Helder and J. Joris Hage, "Sense and nonsense of scar creams and gels," Aesthetic Plastic Surgery, vol. 18, no. 3, pp. 307-313, 1994.

[10] R. Bahramsoltani, M. H. Farzaei, and R. Rahimi, "Medicinal plants and their natural components as future drugs for the treatment of burn wounds: an integrative review," Archives of Dermatological Research, vol. 306, no. 7, pp. 601-617, 2014.

[11] L. Salas Campos, M. Fernándes Mansilla, and A. M. Martínez de la Chica, "Topical chemotherapy for the treatment of burns," Revista de enfermería (Barcelona, Spain), vol. 28, no. 5, pp. 6770, 2005.

[12] Y. Kimura, M. Sumiyoshi, K.-I. Samukawa, N. Satake, and M. Sakanaka, "Facilitating action of asiaticoside at low doses on burn wound repair and its mechanism," European Journal of Pharmacology, vol. 584, no. 2-3, pp. 415-423, 2008.

[13] M. Liu, Y. Dai, Y. Li et al., "Madecassoside isolated from Centella asiatica herbs facilitates burn wound healing in mice," Planta Medica, vol. 74, no. 8, pp. 809-815, 2008.

[14] J. Somboonwong, M. Kankaisre, B. Tantisira, and M. H. Tantisira, "Wound healing activities of different extracts of Centella asiatica in incision and burn wound models: an experimental animal study," BMC Complementary and Alternative Medicine, vol. 12, article 103, 2012.

[15] W. Bylka, P. Znajdek-Awizeń, E. Studzińska-Sroka, and M. Brzezińska, "Centella asiatica in cosmetology," Postepy Dermatologii i Alergologii, vol. 30, no. 1, pp. 46-49, 2013.

[16] A. J. Grossman, "A simplified technique for split-thickness skin graft donor-site care," Plastic and Reconstructive Surgery, vol. 113, no. 2, pp. 796-797, 2004.

[17] J. Mirlashari, A. N. Nasrabadi, and P. M. Amin, "Living with burn scars caused by self-immolation among women in Iraqi Kurdistan: A qualitative study," Burns, vol. 43, no. 2, pp. 417423, 2017.

[18] I. F. K. Muir, "On the nature of keloid and hypertrophic scars," British Journal of Plastic Surgery, vol. 43, no. 1, pp. 61-69, 1990.

[19] K. Jenwitheesuk, P. Surakunprapha, K. Jenwitheesuk, C. Kuptarnond, S. Prathanee, and W. Intanoo, "Role of silicone derivative plus onion extract gel in presternal hypertrophic scar protection: A prospective randomized, double blinded, controlled trial," International Wound Journal, vol. 9, no. 4, pp. 397-402, 2012.

[20] S. Wananukul, S. Chatpreodprai, D. Peongsujarit, and P. Lertsapcharoen, "A prospective placebo-controlled study on the efficacy of onion extract in silicone derivative gel for the prevention of hypertrophic scar and keloid in median sternotomy wound in pediatric patients.", Journal of the Medical Association 
of Thailand = Chotmaihet Thangphaet, vol. 96, no. 11, pp. 14281433, 2013.

[21] J. George, M. Singh, A. K. Srivastava et al., "Resveratrol and black tea polyphenol combination synergistically suppress mouse skin tumors growth by inhibition of activated MAPKs and p53," PLoS ONE, vol. 6, no. 8, Article ID e23395, 2011.

[22] A. Scharstuhl, H. A. M. Mutsaers, S. W. C. Pennings, W. A. Szarek, F. G. M. Russel, and F. A. D. T. G. Wagener, "Curcumininduced fibroblast apoptosis and in vitro wound contraction are regulated by antioxidants and heme oxygenase: Implications for scar formation," Journal of Cellular and Molecular Medicine, vol. 13, no. 4, pp. 712-725, 2009.

[23] D. Bian, J. Zhang, X. Wu et al., "Asiatic acid isolated from Centella asiatica inhibits TGF- $\beta 1$-induced collagen expression in human keloid fibroblasts via PPAR- $\gamma$ activation," International Journal of Biological Sciences, vol. 9, no. 10, pp. 1032-1042, 2013.

[24] C. M. Dang, S. R. Beanes, H. Lee, X. Zhang, C. Soo, and K. Ting, "Scarless fetal wounds are associated with an increased matrix metalloproteinase-to-tissue-derived inhibitor of metalloproteinase ratio," Plastic and Reconstructive Surgery, vol. 111, no. 7, pp. 2273-2285, 2003.

[25] J. Larouche, S. Sheoran, K. Maruyama, and M. M. Martino, "Immune Regulation of Skin Wound Healing: Mechanisms and Novel Therapeutic Targets," Advances in Wound Care, vol. 7, no. 7, pp. 209-231, 2018.

[26] M. Shah, D. M. Foreman, and M. W. J. Ferguson, "Neutralisation of TGF-beta 1 and TGF-beta 2 or exogenous addition of TGFbeta 3 to cutaneous rat wounds reduces scarring," Journal of Cell Science, vol. 108, no. 3, pp. 985-1002, 1995.

[27] M. W. J. Ferguson and S. O'Kane, "Scar-free healing: from embryonic mechanism to adult therapeutic intervention," Philosophical Transactions of the Royal Society B: Biological Sciences, vol. 359, no. 1445, pp. 839-850, 2004.

[28] N. L. Occleston, H. G. Laverty, S. O'Kane, and M. W. J. Ferguson, "Prevention and reduction of scarring in the skin by Transforming Growth Factor beta 3 (TGF $\beta 3$ ): From laboratory discovery to clinical pharmaceutical," Journal of Biomaterials Science, Polymer Edition, vol. 19, no. 8, pp. 1047-1063, 2008.

[29] B. Berman, A. Maderal, and B. Raphael, "Keloids and hypertrophic scars: Pathophysiology, classification, and treatment," Dermatologic Surgery, vol. 43, pp. S3-S18, 2017.

[30] X. Ju-Lin, Q. Shao-Hai, L. Tian-Zeng et al., "Effect of asiaticoside on hypertrophic scar in the rabbit ear model," Journal of Cutaneous Pathology, vol. 36, no. 2, pp. 234-239, 2009.

[31] A. Chuangsuwanich, S. Arunakul, and S. Kamnerdnakta, "The efficacy of combined herbal extracts gel in reducing scar development at a split-thickness skin graft donor site," Aesthetic Plastic Surgery, vol. 37, no. 4, pp. 770-777, 2013.

[32] B. Tang, B. Zhu, Y. Liang et al., "Asiaticoside suppresses collagen expression and TGF- $\beta /$ Smad signaling through inducing Smad7 and inhibiting TGF- $\beta$ RI and TGF- $\beta$ RII in keloid fibroblasts," Archives of Dermatological Research, vol. 303, no. 8, pp. 563-572, 2011.

[33] S. H. Qi, J.-L. Xie, S. Pan et al., "Effects of asiaticoside on the expression of Smad protein by normal skin fibroblasts and hypertrophic scar fibroblasts," Clinical and Experimental Dermatology, vol. 33, no. 2, pp. 171-175, 2008.

[34] J. Song, H. Xu, Q. Lu et al., "Madecassoside suppresses migration of fibroblasts from keloids: involvement of p38 kinase and PI3K signaling pathways," Burns, vol. 38, no. 5, pp. 677-684, 2012.
[35] F. Wu, D. Bian, Y. Xia et al., "Identification of Major Active Ingredients Responsible for Burn Wound Healing of Centella asiatica Herbs," Evidence-Based Complementary and Alternative Medicine, vol. 2012, Article ID 848093, 13 pages, 2012.

[36] J. Gomes, T. Pereira, C. Vilarinho, M. D. L. Duarte, and C. Brito, "Contact dermatitis due to Centella asiatica," Contact Dermatitis, vol. 62, no. 1, pp. 54-55, 2010.

[37] F. Hafeez and H. Maibach, "An overview of parabens and allergic contact dermatitis.," Skin Therapy Letter, vol. 18, no. 5, pp. 5-7, 2013.

[38] Sunilkumar, S. Parameshwaraiah, and H. G. Shivakumar, "Evaluation of topical formulations of aqueous extract of Centella asiatica on open wounds in rats," Indian Journal of Experimental Biology (IJEB), vol. 36, no. 6, pp. 569-572, 1998. 


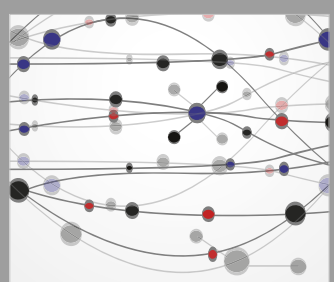

The Scientific World Journal
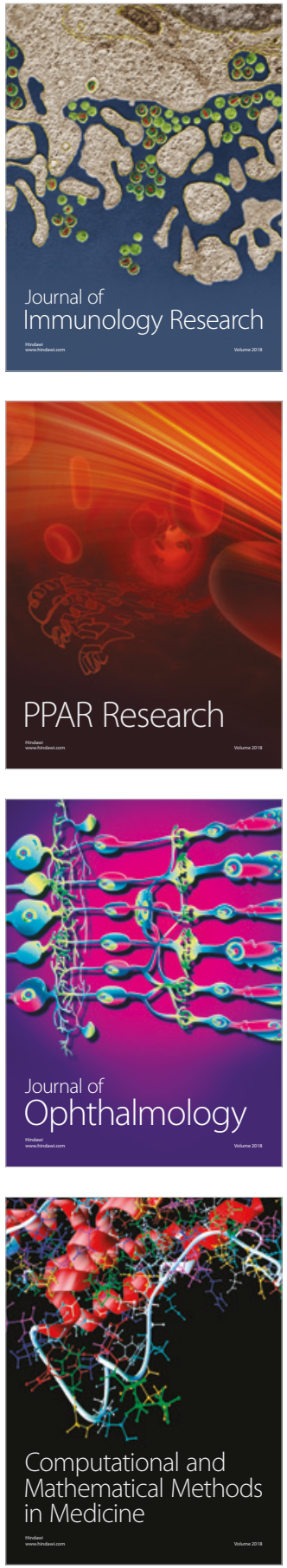

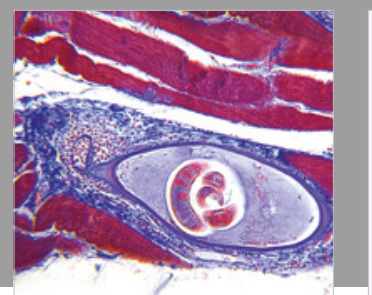

Gastroenterology Research and Practice

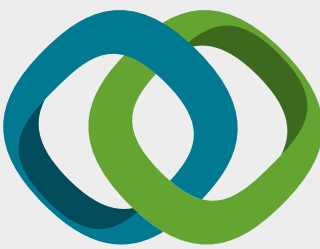

\section{Hindawi}

Submit your manuscripts at

www.hindawi.com
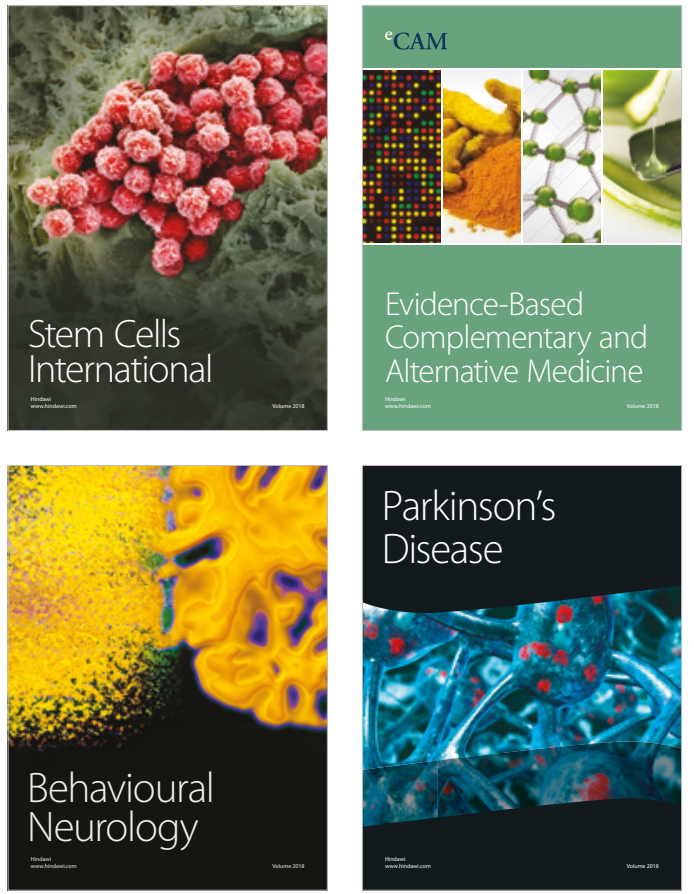

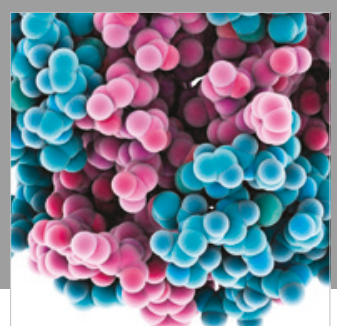

ournal of

Diabetes Research

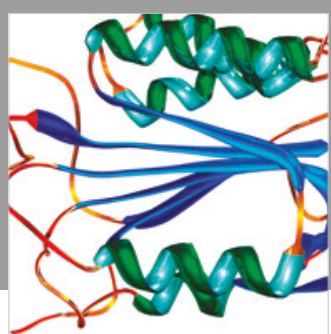

Disease Markers
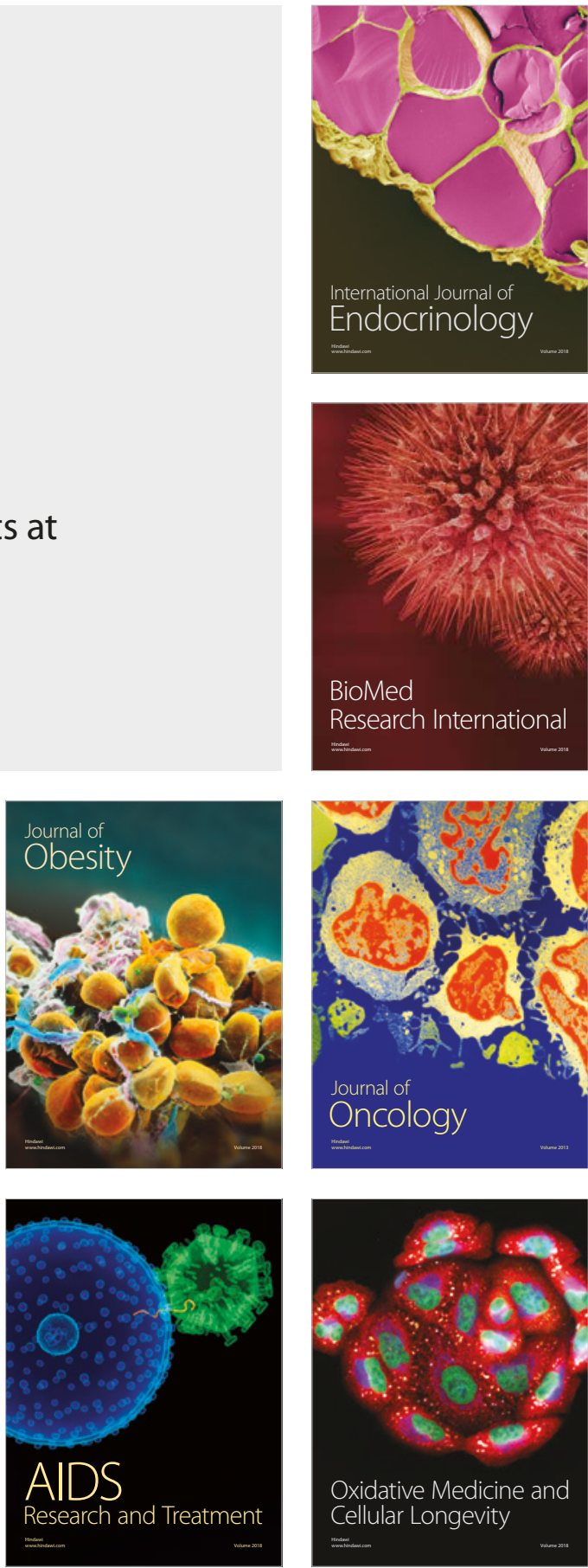